\title{
Emotional factors and continuing professional development
}

\author{
David Taylor
}

It is obvious that learning is an essential part of all successful educational processes, including continuing professional development (CPD). Yet learning can be hard work, especially for the mature adult, and being able to recognise the nature of some of its intrinsic difficulties is likely to be helpful. In educational circles today, it is recognised that engaging experienced or senior people in the educational process of CPD is often difficult.

One reason for this difficulty is simply biological: young animals play and learn more than do older ones. However, this does not account for that antipathy to learning and education so commonly encountered. Neither is the explanation sufficient to understand the anger and scorn, the anxiety and unwillingness about presenting a younger self that can be felt by a senior person whose identity is established as a provider of knowledge, expertise and wisdom. In this context, it is also worth noting the disparity between the amount of rhetoric extolling the value of CPD that comes from the many professional bodies who are making it a requirement of their regulations, and the lack of enthusiasm from their members. It seems that almost the only time professionals can be relied upon to greet CPD initiatives with real enthusiasm is when they are able to argue how it needs to be properly resourced and it is not. This placing of the onerous need for action with the managers and the politicians turns the tables. It is now up to them.

\section{Low uptake of CPD}

The Institute of Industrial Management ran a Certificate of Continuing Professional Development that was taken up by only one person out of a possible 10000 . Only 4\% of members of the Institute of Electrical Engineers and 7\% of members of the Chartered Institute of Marketing registered for CPD programmes. The picture is similar in other organisations, with less than $1 \%$ of the three million active businesses in the UK having registered for the Investors in People award and only $0.1 \%$ being accredited (Watkins et al, 1996). A study by Lancaster University found that apathy and laziness were common among the personal reactions to CPD, while low training budgets, pressures of daily work and lack of financial support characterised the lacklustre reactions of most organisations.

Medical, psychiatric and psychotherapy consultants and other National Health Service (NHS) providers are also susceptible to these reluctant, anxious, or even hostile attitudes to learning and education. While CPD registration among psychiatrists is now rising rapidly, this is mostly because it is increasingly becoming mandatory, and penalties will attach to non-compliance. Filling out CPD returns seems to evoke as much internal resistance as do the Inland Revenue's tax returns.

\section{General trends represented by CPD}

The general trends represented by CPD are occurring in most professions because they arise from largescale socio-economic, political and scientific changes. As technology fuels rapid change and as life expectancies alter demographics, so career and employment patterns are changing quite profoundly,

David Taylor is a consultant psychiatrist and psychotherapist at the Tavistock Clinic (120 Belsize Lane, London NW3 5BA), where he heads the Fitzjohn's Unit, which provides psychotherapy for more serious psychological disorders. He has interests in research and experience in providing theoretical teaching and clinical supervision for senior therapists in Europe and the UK. 
requiring more flexible career planning and more personal development; CPD is one response to these needs. Watkins et al (1996) describe the shift of emphasis that has taken place from single initial qualifying tests of competence to CPD and its benefits. Ad hoc post-qualification learning is being replaced by more structured and formal CPD, with a move from voluntary endeavour to compulsory programmes. Also, CPD is a vehicle for the pressures on professional groups to adapt to the wishes and needs of society. People are becoming much more critical and less trusting of professionals in general and of doctors in particular. As a result, CPD is one of the components of clinical governance (Katona \& Morgan, 1999; Wattis \& McGinnis, 1999).

Therefore, formalised lifelong learning programmes will be conducted in an atmosphere of surveillance; almost all education seems to require and attract some element of compulsion and fear. Social, cultural and political pressures mediated by inducing feelings like these do go some way towards explaining the general reluctance and grumpiness about CPD, but how are we to understand more deeply - at a more universal and psychological level - the generally encountered resistance to learning?

\section{Education - real motivation in a real context}

Most adult educational thinking and practice presupposes the existence of a coherent, authentic and rational self, able 'rationally, autonomously and independently' to learn from experience (Illeris, 1999), and certainly this seems to be the assumption in most professional and governmental advocacy of CPD. A moment's reflection on everyday life shows that this assumption simply is not justified. Prominent educational theorists have argued that the self is irrational, emotional, embedded in a body with needs, and socially and societally dependent (Usher et al, 1997). Our perception of reality is similarly fragmented and unstable, and so the human perceiving self is always searching for a meaning, never at rest, and is haunted by all the apparent choices, of which very few are really attainable. This picture does seem more true to life than the rationalist perspective more usually adopted. Provided that this point of view is not used to justify intellectual laziness or to negate the constant need for new learning, it can help us be more realistic in our everyday experience of educational goals. It can help us identify the ways in which they are truly uncertain, changeable or displays of power and dominance.
When discussing CPD in psychiatry from the rationalist perspective, it is laudable to commend opportunities such as its contribution to improving the standard of psychiatric care. For CPD is surely a legitimate way of achieving goals that are social as well as individual. For instance, and relevant to the thinking in this article, it can be seen as helping to repair that integrated psychosocial and biological framework of understanding and clinical management that seems to have broken down in British psychiatry. Others may wish CPD to contribute to different attitudes to the use of evidence. However, when seen from the alternative point of view described above, these advocacies may seem naïve, political or even mendacious. And quite irrespective of one's agreement or disagreement with the particular aim proposed, it is obvious, even to the psychologically blind, that we all harbour or nourish 'irrational' resistances to the aims of CPD which we employ to subvert them. Understanding the nature of these might help.

\section{Learning or development?}

The relationships that exist between learning processes and developmental ones are crucial, but not well understood. The designation CPD itself emphasises development - the unfolding, growth and realisation of an individual's capacities within his or her life span - rather than the learning of items of knowledge only. Most educational methods regard learning and developing as related, yet different. However, beyond agreeing about their fundamental interconnectedness (although a lot of valuable experience has been accumulated from the classroom and from traditional professional or guild apprenticeships), not much is definitely understood. Does one learn the ability to listen to others or is it developed? Can one teach flexibility? How does one teach the ability to lead a multi-disciplinary team? Much more than semantic precision is required to answer questions like these.

Psychologists and educationalists who specialise in learning processes have a contribution to make. Here I will argue that an understanding of psychodynamic factors involved in the acquisition of knowledge can be helpful in understanding some of the problems that arise in adult learning. Obviously, this approach will be particularly relevant to those parts of the CPD agenda concerned with the development of personal qualities, but powerful emotional factors are still to be reckoned with, even in the acquisition of specific seemingly objective items of knowledge or skills. 


\section{Psychoanalytic ideas about learning and development}

The capacity to learn from experience is an essential ingredient for the kind of personal development and change that is sought in most psychodynamic therapies and in psychoanalysis. For this reason, a number of psychoanalytic studies (Bion, 1962; Britton, 1998) have focused on the emotional aspects of learning processes and on the deep-seated ambivalences that exist about psychological growth. This body of work offers important insights into the inner structure of the psychology of learning from experience, whether it be the experience of repetitive neurotic relationship patterns in everyday life or in the specialised setting of the consulting room. It provides a framework in which the resistances to learning that are inevitably encountered can be acknowledged, accepted, understood and, to a degree, modified, rather than denied or ignored. (See SalzbergerWittenburg et al (1983) for a useful monograph on the emotional aspects of learning and teaching.)

Psychodynamic psychotherapy, like psychoanalysis, is a form of treatment in which, through a specially observed relationship, the therapist and the patient become familiar with the patient's ways of relating, often unconscious or unformulated. The repetitiveness of some of these, usually involving the individual's deepest wishes and desires, is but one indication of the extreme difficulty of learning new ways in the sphere of human relations. There are many reasons why people find it very difficult to change the way they relate to others. This intractability may be explained by invoking a general lack of plasticity in the neuronal underpinnings of these habitual reaction patterns or ways of perceiving the world. However, when someone for a few moments does achieve some new emotional learning or insight, it is often overwhelmed by amazingly powerful counter-reactions, arising from within, that possess a dynamic life and a motivational lawfulness all of their own. Unless we reckon with reactions like these and struggle to understand the deep-seated motivational factors that seem to underpin them, we are missing out on crucial areas of enquiry. These areas include unconscious mental functioning and the ubiquitous denial and censorship operating in our conscious mental life.

Undeniably, human beings have a love of learning (and of books). It is probably part of our basic motivational systems. But in psychoanalytic treatments, as well as this love, we witness a hatred of new knowledge operating in these counterreactions. New knowledge and the process of arriving at it seem to stir up hatred and dislike, which are employed to undo insight and the prospect of personal change. Psychological growth and maturation too are ambivalently regarded. Perhaps this is not so surprising when we consider that much new learning involves learning of unpleasant things, with elements of loss, limitation, not being in control or not possessing. When someone knows better than us, is more intelligent or more perceptive, this can open up a narcissistic wound and lead to hostile and/or fearful reactions out of rivalry. And we certainly should know that these phenomena are not trivial, mere peculiarities limited to the consulting room. In the 'right' historical and social conditions, the hatred of knowers, and of their knowledge, can become a dangerous social or political force. Books, after all, have been burnt as well as cherished.

Quite aside from its particular reference, knowledge in general has meanings of its own. Knowing can be equated with possession and just as 'to know' means 'to have' in the biblical sense, so the psychological meaning of not knowing, or of ignorance, can be felt like a sting, because it represents the loss of possession of the loved object. In these ways, all learning processes, no matter how apparently routine, objective or remote from the individual's personal concerns, are subject to powerful unconscious factors.

One way of regarding social, personal and intellectual curiosity and the learning consequent upon them is as crucial expressions of our evolutionary adaptiveness. One of their essential contributions to adaptiveness is to equip the developing human infant and child with the capacity to function within family groups. It is well known that psychoanalysts consider the Oedipus configuration - the triangular patterning of relationships, dominance, rivalry and jealousy - to pervade our relationships within family groups. A less wellknown implication of this idea is that the social learning ability of the mature adult grows out of the developing child's ability to recognise and to process the emotional dynamics that are part and parcel of his or her Oedipal relationships. This is a developmental task that requires considerable environmental assistance and support from his or her mother and father. Failure to manage these dynamics accounts for some conflicts about being in new learning situations in adult life. Learning always occurs within a contextual framework of relationships with others, and powerful transference elements derived from early family relationships exist in the relationship between teacher and pupil and between pupil and pupil.

All of these matters may be especially problematic in a subject like psychiatry, where new learning often 
needs to be learning about people and not about things. Learning about people necessarily evokes personal resonance and unresolved social and personal anxieties are revived (see Box 1 ).

\section{Emotional factors in learning: a case illustration}

I will describe the operation of some of these factors by drawing upon my experience of providing clinical supervision and case discussion workshops for qualified senior psychotherapists and psychoanalysts, including consultants in Europe and colleagues in different parts of the UK.

These workshops usually they have six to eight members, but they may include up to 15 . Their frequency varies from fortnightly to bimonthly. Although the discussion of scientific papers may play some part, the seminars are mainly clinical. Usually, members take turns to present a patient in an ongoing psychotherapeutic or psychoanalytic treatment. Although explicit self-revelation is not part of the culture of these seminars, it is clear that presenting a detailed report of single sessions, including reported speech such as "She said... I said...", involves considerable exposure of oneself to the gaze and judgement of one's colleagues. Also, group dynamics operate on individual members' subjective experiences in powerful ways.

Questionnaire-based evaluations carried out for the purpose of audit, as well as informal reports and impressions, in general strongly support the value of these case discussions and formal teaching to practising therapists. For example, in one questionnaire evaluation of a CPD course, members reported many beneficial changes in their understanding and in their own teaching skills; there was least change in their judgement of how they saw themselves functioning with their patients.

However, detailed enquiries about anticipatory attitudes before a series of case discussion seminars started revealed widely reported expectations of unsafeness, of criticism from other group members, and of a lack of trust and honesty. Many respondents were anxiously expecting narcissism and competition within the group. Most reported that their initial anxieties diminished as they gained experience of the group itself. But while the majority began quite rapidly to appreciate what the group was beginning to accomplish, a minority reported that their anxieties increased rather than diminished. For these individuals, the learning experience, supposed to be beneficial, was humiliating, debilitating or downright destructive. Some - in
Box 1 Learning and emotional conflict

All learning situations are emotionally highly charged - learners tend to feel very anxious about not knowing or appearing inexpert

Accepting the need to learn new things and gain new skills is intrinsically difficult

Powerful ambivalent attitudes of love and hate exist towards knowledge

If learning new data leads to a paradigm shift, it will be experienced as a threat (Kuhn, 1962); at these points, pre-existing personal identities and views of the world can no longer be maintained and new adjustments have to be found

contrast to the majority - reported an experience of insensitive teaching, of an arrogant or superior teacher using rigid and opaque jargon to preach an alien dogma. A few felt stripped of capacities - deskilled - while a greater number had felt this to be a risk. Of course, aspects of these reactions are often quite clearly evident in the case discussions themselves. Members withdraw, are absent, drop out, are anxious, attention-seeking or argumentative, dominate, are awkward or they complain.

Sometimes, in the group setting itself, it is possible to observe directly how difficult it is for members to tolerate the state of disequilibrium that is a concomitant of any significant new learning. For instance, one group member would repeatedly intervene, disrupting any discussion about a patient whenever it was deepening and coming to fruition. In this particular person, unconscious envy appeared to be an important factor, but there are many other reasons why the individual pull towards re-establishing the psychological status quo is very strong.

These adverse reactions to a learning situation can be compared with an adverse reaction to a medication. It is important to consider carefully the possibility that the prescriber has got it fundamentally wrong; and in the case of learning, to consider the possibility that one's perceptions may be incorrect. But this is seldom the whole story. The idiosyncrasies of the learner and the fundamental difficulties of the learning situation need to be taken fully into account for these reactions to be understood properly. For example, there is usually some sort of adverse reaction in any group, no matter how it is taught or who teaches it. While the individual who most obviously manifests the 'allergy' may have specific problems, he or she can also be regarded as giving voice to that particular feeling, 
which exists in most of us, that we find that being taught is cruelly exposing.

Also, relationships between the members in their professional contexts outside the group play a part in how the group functions. The members of a case discussion seminar will usually have some kind of working contact with each other outside the seminar, and their position within their organisation will affect their status within the group. The membership may be multi-disciplinary. It may encompass quite different levels of competence and talent, and these differences often will not correspond at all well with the seniority, status and external organisational position of the members. Sensitivities and anxieties about these disparities can have a big effect on the workshops and the individuals within them. However, even when these problems loom large, a case discussion group may still develop a sense of itself and its working methods, thus making its members more resolute and yet tactful in facing difficulties of this sort. The development of this growing authority can itself constitute a threat to the organisational status quo. These are the destabilising effects of change.

It is not helpful or appropriate to focus on these reactions to the learning situation in the case discussion group itself, although there will be times when attending to or discussing these matters becomes necessary because the work of the group is impeded by them. The real work of the group, its primary task, is to discuss cases psychotherapeutically or psychoanalytically and to learn from that discussion. However, if the teacher is able to recognise and understand these problems, he or she can reach a degree of genuine tolerance of their existence, rather than bending over backwards to avoid them by trying to be liked or appreciated, or alternatively becoming confrontational or in some other way anxious or disturbed. Often, the group itself will sense difficulties in itself or its members and will, through subtle alterations, modify its behaviour so that a more thoughtful attitude is made more possible.

\section{Understanding learning fears}

In psychoanalytic work, it is a daily occurrence for what the analyst thinks of as a helpful comment to be experienced by the patient as critical, hurtful and destructive. In certain situations with some patients, it can be difficult to find any way of talking that is not felt to be hostile or hurtful. Britton (1998) has graphically described how a patient in this state feels that the analyst is an incarnation of malignant misunderstanding. This telling phrase captures the essence of one of the fundamental problems encountered in the learning situation.

A learning situation is disliked, creates anxiety or is avoided because it exposes us to our incapacities. Recollecting how it can feel when one is trying to speak a foreign language can evoke some of the qualities of the experience. We can feel so at a loss, so inept, diminished and confused, as yet again we fear we will not comprehend or will not find the word. And when we do not comprehend, we feel excluded from the others who can communicate with each other. These disorienting occasions can easily bring out underlying paranoid and infantile reactions, much as they can do in migrants. The tendency to react to the unfamiliar with fear and hostility is very strong and, in a certain sense, is normal. It can easily override all attempts to make new learning easier. In fact, elaborate efforts to make learning easy often feel false because they seek to deny the psychological reality of these difficult feelings. Much new learning is neither accessible, nor easy, nor should it be. Indeed, learning how to cope with its difficulties is one of its necessary rewards.

A normal transference/countertransference relationship in a supervisory relationship between one consultant and another is like that between a parent and a grown-up child with a family of his or her own, whereas earlier in a person's training it is more like the relationship between a parent and a young child. Clearly, a to-and-fro relationship of this sort is bound to have many transference elements, and sometimes these will have the potential to become intense or disturbed. Most often, the powerful feelings of rivalry with any figure who is perceived as knowing are kept at bay by narcissistic defences, by idealisation or by a kind of socially condoned devaluation, so that the perceptions of difference that cause trouble are diminished. In a situation aiming to lead to new learning, these protective defences may not be useful or even sustainable (see Box 2).

\section{Are consultant psychiatrists immune?}

It might be comforting to conclude that consultant psychotherapists are especially sensitive and that it is only they who find learning disturbing, but it would not be true. For instance, it is fairly clear that the multi-disciplinary community mental health teams that are at the centre of 'care in the community' need leadership and that if psychiatrists do not 
Box 2 The infantile resonance of knowledge and its acquisition

The relationship between teacher and student is full of transference and countertransference, based on reactions to the original gap between the knowing, capable parent and the pre-skilled and learning child

Knowing or not knowing connect with desired Oedipal triumphs or dreaded defeats and correspondingly with gains or losses of infantile omnipotence

Knowing and competence are equated with possessing or having control over the thing or person known

provide this then leadership will pass to other professionals. Yet, it continues to be a standing joke among community mental health team staff that consultants are often absent from work discussions and organisational meetings concerning them (many exceptions notwithstanding), often giving the reason that they are busy, even though these meetings may be realistic efforts to raise standards of care, treatment and morale. Although the consultant psychiatrist really is busy, the excuse is almost always a rationalisation. Anxieties about being in a team, a group where customary and familiar hierarchies may be changing, are revealed by the consultant functioning in a stereotyped way, as the one with all the expertise and unable to listen and learn from others.

It is true that sometimes a mental health team can function well with a split in roles, with the nurses, social workers, occupational therapists and psychologists looking after the interpersonal relations and psychosocial aspects, while the consultant carries the ultimate responsibility for the medication and the statutory requirements. The consultant gets his or her CPD elsewhere and in relation to other subjects, at conferences or College meetings.

One way of understanding the split between those concerned with the physical aspects of mental illness and those who are concerned with the psychosocial dimension is that it is a group defence against the full impact of primitive and intense anxieties connected with mental illness. It can be a legitimate way of dividing the burden. Looking after people with a mental disturbance, especially when the disabilities involved are chronic, is perhaps more disturbing and distressing than we often are aware. However, as the demands on mental health staff have increased, a division of labour of this sort is less likely to work. For today's mental health teams have such a difficult job to do in such a difficult climate that they could be enormously helped (and, of course, they often already are) by the authority, intelligence and resourcefulness that consultant psychiatrists knowledgeable and skilled in team and interpersonal dynamics could provide (Temple, 1999).

The reasons why some consultants tend to stay away from arenas that involve personal learning have some connection with the persistence of a traditional conception of the consultant's role, but personal vulnerabilities undeniably play a part. Paradoxically, some psychiatrists are especially anxious or uncomfortable with the disturbance associated with primitive emotions. The need to acknowledge this and to do something about it in the course of training is sometimes side-stepped by a profession-wide defence of adopting a supposedly scientific attitude, in supposedly rational contrast to the alleged softness of psychosocial or psychodynamic thinking. While these vulnerabilities often should be respected, it also needs to be acknowledged that they may interfere with the task (see Box 3).

\section{Concluding remarks}

In this paper, I have tried to describe the emotional resistances that may limit our ability to expose ourselves to experiences of new learning. Although essentially there is no difference between a consultant and anyone else, consultants are in a sensitive position within NHS training structures. Their difficulties may be even more marked because consultants are people who have sought out and achieved an established and senior place in the

Box 3 Controversial issues

Learning is not a rational process: it is powerfully affected by unconscious factors

Inhibitions and difficulties about undertaking significant new learning are greater in consultants than in training grades

It is a rationalisation that the resourcing of CPD limits its uptake by consultants: emotional resistance and reluctance are more important

CPD should be used to repair the psychosocial model in psychiatry 
hierarchy. Becoming a consultant is a rite of passage in which the newly appointed consultant is supposed to be fully 'grown-up'. There is a powerful fantasy that being a consultant means having become adult, which in turn means having to know all the answers and have all the capacities.

But what becoming a consultant actually entails is changing. Consultants increasingly have to function with an explicit role as part of a team and a service. This requires the ability to move with some flexibility between the different roles of being the ultimate authority in one context, a colleague in another and an ordinary team player in yet others, all while displaying a wide range of clinical, research, teaching, management and leadership skills.

It is inevitable that keeping these skills up to date will require demanding periods of learning and then re-learning. It may be that much more explicitly stressing (and giving thought to) the fact that teams, services and regions, just as much as individuals, have complex and changing developmental needs could relieve some of the burden of the individual's anxiety about CPD, as well as contributing to a developmental programme for the service or the region. Then CPD would be undertaken as much to equip the team to function better as satisfy what is required of or by the individual.

The wish to understand more or to do something well, or the realistic recognition of a deficiency in what we are capable of, are powerful reasons that make us want new learning in general or, in the context of this subject, to take part in CPD. These positive motivations can be very strong, but they have to contend with countervailing tendencies in which we may be too grandiose to recognise that there is more for us to know. Furthermore, most of us also feel our deficiencies too keenly and therefore feel vulnerable if we expose ourselves to the view we have of ourselves as flawed, failing, inadequate, stupid, lazy or not up to the job. We anticipate that new learning will involve running the gauntlet of these fears and beliefs and testing their reality.

\section{References}

Bion, W. R. (1962) Learning from Experience (reprinted 1984). London: Karnac.

Britton, R. (1998) Belief and Imagination. London: Routledge \& New Library of Psychoanalysis.

Illeris, K. (1999) Laering. Roskilde, Denmark: Roskilde University Press.

Katona, C. \& Morgan, G. (1999) The future of CPD (editorial). Advances in Psychiatric Treatment, 5, 161-162.

Kuhn, T. S. (1962) The Structure of Scientific Revolutions (2nd edn). Chicago, IL: University of Chicago Press.

Salzberger-Wittenburg, I., Henry, G. \& Osborne, E. (1983) The Emotional Experience of Learning and Teaching. London: Routledge.
Temple, N. (1999) Should consultant psychiatrists be trained in psychotherapy? Advances in Psychiatric Treatment, 5, 288295

Watkins, J., Drury, L. \& Bray, S. (1996) Continuing professional education. In The Future of the UK Professional Associations (ed. J. J. Watkins), pp. 49-63. Cheltenham: Cheltenham Strategic Publications.

Wattis, J. \& McGinnis, P. (1999) Clinical Governance and continuing professional development. Advances in Psychiatric Treatment, 5, 233-239.

Usher, R., Bryant, I. \& Johnston, R. (1997) Adult Education and the Post-Modern Challenge. London: Routledge.

\section{Multiple choice questions}

1. According to recent psychoanalytic thinking, factors that affect emotional learning include:

a identification

b hostility towards knowledge

c love of knowledge

d Oedipal curiosity

e reinforcement schedules.

2. In general psychiatry, a psychotherapeutic perspective may be especially useful when:

a trying to diagnose an organic brain syndrome

$\mathrm{b}$ team members are frequently absent from ward rounds

c team members have opposing view-points about an acting-out patient

$\mathrm{d}$ a patient with depression fails to respond to medication

e trying to support colleagues in other disciplines.

3. In psychotherapy case discussion groups:

a consultants are always the most competent

$\mathrm{b}$ the leader concentrates on trying to analyse the learning difficulties in the group

c identification with the group leader is common

d consultants should never be in a group with others of lesser seniority

e emotional factors do not significantly affect what is learnt.

$\begin{array}{lll}\text { MCQ answers } & & \\ & & \\ \text { 1 } & \text { 2 } & \text { 3 } \\ \text { a } T & \text { a F } & \text { a F } \\ \text { b T } & \text { b T } & \text { b F } \\ \text { c T } & \text { c T } & \text { c T T } \\ \text { d T } & \text { d T } & \text { d F } \\ \text { e F } & \text { e T } & \text { e F }\end{array}$

